\author{
А. Э. Цумарев \\ Институт русского языка им. В. В. Виноградова РАН \\ (Россия, Москва) \\ zumarew@yandex.ru \\ Л.Л. Шестакова \\ Институт русского языка им. В. В. Виноградова РАН \\ (Россия, Москва) \\ lara.shestakova@mail.ru
}

\title{
ОСОБЕННОСТИ ПОДАЧИ ГРАММАТИЧЕСКОЙ ИНФОРМАЦИИ О СЛОВЕ В «АКАДЕМИЧЕСКОМ ТОЛКОВОМ СЛОВАРЕ РУССКОГО ЯЗЫКА»
}

В статье рассматриваются особенности представления грамматической информации о слове в новом «Академическом толковом словаре русского языка» (АТоC), относящемся к числу средних по объему толковых словарей. Обсуждаемые особенности отличают создаваемый словарь от предшествующего четырехтомного «Словаря русского языка» (МАСа), изданного Академией наук в 1980-е гг. Грамматическая информация о слове содержится в АТоСе в двух зонах словарной статьи - зоне грамматических форм и зоне грамматических характеристик; она соответствует современной языковой норме и дается полнее и нагляднее, с большей последовательностью, чем в словаре-предшественнике. Это достигается как за счет систематического использования традиционных лексикографических средств, так и благодаря введению новых средств и способов наглядного представления грамматических сведений о слове. Новые способы применяются при описании формы родительного падежа единственного числа существительных. Например, в случае подвижного формообразовательного ударения словарная статья содержит указание финальной части слова, вместо традиционного указания лишь на флексию (БЕЛОВИ́К, -в и ка́). В словаре нашел отражение морфологический признак одушевленности, в качестве средства обозначения которого используется помета одуш. (БА́БОЧКА ... 1. Одуш. Насекомое с двумя парами крыльев). В значительном числе случаев возникает необходимость восполнения пробелов в описании грамматической стороны слова. В частности, в словаре более последовательно отражаются: наличие кратких форм у имени прилагательного (БЕЗДУХО́ВНЫЙ, -ая, -ое ; -вен, -вна, -вно); ограничение в употреблении форм 1-го и 2-го 
лица у глагола (ГЛо́хнУТЬ ... 2. ... (1 и 2 л. не употр.) Становиться неслышным (о звуках); затихать); конструктивная обусловленность лексического значения (БАССЕ́ЙН ... 3. какой. Область залегания каких-л. определенных полезных ископаемых); специфика синтаксической связи управления (ГРОЗЙТЬ ... 1. ... кому чем, с неопр. или с придаточнылм изъяснительнылм. Предупреждать с угрозой о чём-л. тяжелом, страшном; угрожать). Приведенные в статье примеры свидетельствуют о необходимости усовершенствования традиционного грамматического описания лексики в ходе работы над новым толковым словарем русского языка.

Ключевые слова: современный русский литературный язык, грамматика, грамматическая норма, взаимодействие лексики и грамматики, лексикография, толковый словарь, словарная статья.

В 2016 г. вышли из печати 1-й и 2-й тома «Академического толкового словаря русского языка» (АТоС), работа над которым ведется в ИРЯ им. В.В. Виноградова РАН. В этом словаре, задуманном как продолжение «Словаря русского языка» под ред. А.П. Евгеньевой (МАС), предполагается представить многостороннее описание лексики современного русского литературного языка. Неотъемлемая часть такого описания - грамматическая информация о слове, соотносимая с двумя зонами словарной статьи: грамматических форм и грамматических характеристик.

При общей традиционности в оформлении этих зон они в определенной степени обновлены. Информация в них дается, в интересах пользователей словаря, полнее и нагляднее, с большей последовательностью, чем в словаре-предшественнике. Источниками грамматических сведений, включаемых в АТоС, являются как грамматики русского языка, так и словари разных типов, фиксирующие грамматические характеристики слов (словари грамматических трудностей, толковые, орфографические и др.). Предпочтение отдается современным изданиям, в том числе словарям, вышедшим на рубеже XX-XXI вв.

Обновление грамматических зон осуществляется в АТоСе по-разному, в соответствии с принятыми правилами. Так, несколько из них связаны с грамматическим описанием существительных, в частности, с подачей формы родительного падежа единственного числа. В соответствии с одним из правил форма родительного падежа имеет вид финальной части слова, начиная со слога, на который падает ударение в именительном падеже:
БАШЛЫ'亡к, -л ы ка́ ;
БЕЛОВЙК, -в и ка́ ;
ГАМА́K, -м а ка́;
ГОПА́К, -п а к á
cp.:

БУТЙк, -т и́ ка и (разг.) -т ика́.

Другое правило касается составных наименований (сложносоставных слов) с дефисным написанием. Поскольку в некоторых из таких слов склоняется только 
вторая часть, а в других - обе части, форма их родительного падежа приводится полностью:
А́ЛЬФА-ЧАСТИ́ЦА, а́льфа-части́цы;
БЙЗНЕС-КЛАСС, би́знес-кла́сса;
БОЙ-БА́БА, бой-ба́бы;
КРЕ́СЛО-КАЧА́ЛКА, кре́сла-кача́лки;
МА́ТЧ-РЕВА́НШ, ма́тча-рева́нша.

В описании качественных прилагательных (и относительных, приобретающих значение качественности) более последовательно, по сравнению с четырехтомным словарем, представлены краткие формы. Вот несколько статей, в которые введены такие формы, в том числе имеющие варианты:

БЕЗВРЕ́МЕННЫЙ, -а я, -о е; -м е н е н, -м е н н а, -м е н н о ;

БЕЗЗАВЕ́ТНЫЙ, -а я, -о е; -т ен, -т на, -т н о;

ГОМОГЕ́ННЫЙ, -ая, -ое; -нен, -нна, -нно;

БЕЗДЕ́ЙСТВЕННЫЙ, -а я, -о е; -в е н и - е н ен, -в е н на, -в е н н о;

БЕЗЛЙСТВЕННЫЙ, -а я, -о е; - в ен и -в енен, -в енна, -в енно.

Ср. и новые статьи прилагательных, имеющие в зоне грамматики информацию о наличии кратких форм:

БЕЗАЛЬТЕРНАТЙВНЫЙ, -а я, -о е; -в е н, -в н а, -в н о;

БЕЗДЕФЕ́КТНЫЙ, -а я, -о е; -т е н, -т н а, -т н о;

БЕЗДУХО́ВНЫЙ, -а я, -о е ; -в е н, -в н а, -в н о ;

ГЙПОАЛЛЕРГЕ́ННЫЙ, -ая, -ое; -ге́нен, -ге́нна, -ге́нно.

Одна из установок словаря - это иллюстративное подтверждение тех или иных сведений о слове, в том числе вновь вводимых в словарные статьи. Это касается и упомянутых форм. Так, в грамматическую зону статьи «Безденежный» были введены краткие формы. Они реализуются только во втором значении 'не имеющий денег, нуждающийся в деньгах', где и проиллюстрированы цитатой:

БЕЗДЕ́НЕЖНЫЙ, -а я, -о е; - ж е н, - жн а, - ж н о. 1. полько полн. ф. Фин. То же, что без наличны й. Безденежный расчет. Безденежная банковская операцุия.

2. Разг. Не имеющий денег, нуждающийся в деньгах. Безденежный человек. Мамины сестры, тетя Анюта с больной дочерью на руках и тетя Женя с двумя дочерьми --- тоже были довольно безденежны; семья тети Жени включала еще бабушку, которой не полагалось пенсии. И. Дьяконов. Книга воспоминаний. || Характеризующийся отсутствием денег. Декабрь был самый люто безденежный месяи в моей жизни. К. Воробьев. Вот пришел великан.

Обновление коснулось в АТоСе и грамматических характеристик слов. В словаре нашел отражение признак одушевленности, приписываемый существительным, винительный падеж которых совпадает с родительным (см. раздел «Как пользоваться 
словарем». Т. 1, с. 15-16). Передающая этот признак помета одуи. последовательно ставится при словах, лексическое значение которых заключает в себе понятие о живом. Данная помета используется в АТоСе вслед за Л.П. Крысиным, применившим ее в «Толковом словаре иноязычных слов», и может занимать разные позиции в словарной статье - при слове (в том числе многозначном) - балерина, бобик, голубь; при отдельном значении (или оттенке значения) - бабочка, бобёр, бас; при употреблении слова в значении другой части речи - бедный, большой, глухой:

БАЛЕРИ́НА, -ы, ж., одуш. Артистка балета;

БО́БИК, -а, м., одуш. Разг. О собаке, обычно беспородной (по распространенной кличке);

ГО́ЛУББ, -я, род. мн. -е́й, м., одуш. 1. Птица средней величины с разнообразной окраской оперения (обычно серовато-голубой или белой) и большим зобом. ...

2. (обычно в обращцении). Разг. Ласковое название мужчины.

БА́БОЧКА, -и, род. мн. -ч е к, дат. -ч ка м, ж. 1. Одуш. Насекомое с двумя парами крыльев. ...

2. Разг. Галстук в виде небольшого банта;

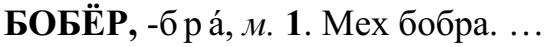

2. Одуш. То же, что б о бр;

БАС, -а, мн. басы́, м. 1. Самый низкий по звучанию мужской голос. ... $\|$ одуш. Певец с таким голосом.

БЕ́ДНЫЙ, -а я, -о е; ... | в знач. сущч. О человеке: бе́дный, -о г о , м., одуш. Oneкать бедных;

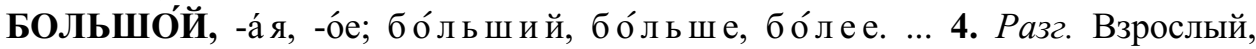
а также вышедший из младенческого возраста, подросший (о ребенке). ... | в знач. сущ.. большие, -и́ х , мн., одуш.;

ГЛУХО́Й, -á я, -о́ е; ... | в знач. сущ̧. глухо́й, -о́ го, м., одуш.; глуха́я, -о́ й, ж., одуи. Школа для глухих.

Введение в состав грамматических характеристик слова признака одушевленности важно и для разграничения омонимов. Ср.:

БОЛТУ́Н

БОЛТУ́НЬЯ², -и, род. мн. -н и й, дат. -н ь я м, ж. Разг. Яичница, взбитая на молоке и помешиваемая во время приготовления.

ГАЗЕ́Л $\mathbf{b}^{1},-$-и, ж., одуш. Горная коза из породы антилоп;

ГАЗЕ́ЛЬ², -и, ж. 1. Лит. Стихотворная форма в восточной поэзии;

ГАЗЕ́Л ${ }^{3}$, -и, ж. Разг. Полугрузовой автомобиль.

Особое внимание уделяется в словаре информации, маркирующей грамматические ограничения в реализации значений, оттенков значений, употреблений слов, 
а также значений фразеологических сочетаний. Набор соответствующих помет, используемых при описании существительных, прилагательных, глаголов, широк: только ед. ч., обычно мн. ч., только полн. ф., обычно кратк. ф., обычно повел. и т.д., например:

ВБ́ГГОВОР ... 1. только ед. ч. Манера, характер произношения звуков, слов языка. Парижский выговор;

БАНА́ЛЬНОСТЬ ... 2. обычно мн. ч. (б а н а́ л ь н о с т и , -е й ). Банальное выражение, банальная мысль. Говорить банальности;

ГОТО́ВЫЙ ... 3. обычно кратк. ф. Приготовленный, годный к употреблению, использованию. Обед готов;

ГЛУБО́КИЙ ... 1. ... || только полн. ф. Спец. Производимый на значительную глубину. Глубокая вспашка. Глубокое бурение;

ГЛАЗ ... $\diamond$ Разуть глаза (прост. неодобр.) (обычно в повелительном предложении) - посмотреть внимательно, как следует. - Не косите на чужой земле. Как так - на чужой? --- Не видишь, где межевой столб стоит? - А он и говорит: «Ты сам разуй глаза и погляди, столб-то позади тебя стоит». М. Шолохов. Поднятая целина.

Также отмечаются грамматические употребления слова в пределах выделенного значения, например:

БЕСПЕРСПЕКТЙВНО. Нареч. $\kappa$ бесперспективный. - А Саша дома? Сама на работе, - ответила [мамаша] очень вежливо и даже как бы сострадая, что Алена до сих пор не обзавелась семьей, а бесперспективно бегает за ее сыном. В. Токарева. Тайна Земли. | в знач. сказ. Любовь диктует свои правила, и навязывать ей свои - глупо, рискованно, бездарно и действительно бесперспективно. М. Голованивская. Я люблю тебя;

ГОВОРИ́ТЬ ... 2. ... Выражать в устной речи какие-л. мысли, мнения, сообщать факты и т. п. ... | Употребляется в форме 1 л. ед. ч. наст. вр. для усиления требования, приказания (часто повторного). ... - Tы куда! Стой! Стой, говорю! - кричала бабушка. Я мчался во весь дух. В. Астафьев. Последний поклон;

ГОРЧЙТЬ ... Иметь горьковатый вкус. Масло горчит. Мука горчит. ... | в безл. употр. Где-то в груди горчило, будто она [Настена] наглоталась дылму. В. Распутин. Живи и помни.

Составители словарных статей стремятся к восполнению пробелов в указании на грамматические ограничения значений, к систематичности в постановке названных и других подобных помет. Это касается, например, пометы (1 и 2 л. не употр.), которая отражает грамматическое ограничение, обусловленное лексической семантикой слова. Эта помета по необходимости была введена в целый ряд статей: БЕЖА́ТЬ (2-5, 7 значения), БИТЬ (два оттенка в 1 значении, 9 и 10 значения), ГАЛДЕ́ТЬ (употребление 'О птицах'), ГЛО́ХНУТЬ (2-5 значения) и т. д.:

ГЛО́ХНУТь, -ну, -нешь; прош. глох и гло́хнул, гло́хла, -ло; несов. 1. (сов. оглохнуть). Терять способность слышать, становиться глухим. ... 
2. (сов. заглохнуть) (1 и 2 л. не употр.) Становиться неслышным (о звуках); затихать. ...

3. (сов. заглохнуть) (1 и 2 л. не употр.) Разг. устар. Гаснуть, потухать. ...

4. (сов. заглохнуть) (1 и 2 л. не употр.) перен. Постепенно исчезать; постепенно слабеть, уменьшаться. ...

5. (сов. заглохнуть) (1 и 2 л. не употр.) Зарастать сорными травами, приходить в запустение. ...

Важной задачей для авторов словаря является указание на конструктивную обусловленность лексического значения - явление, которое служит еще одним наглядным примером взаимодействия лексики и грамматики. Несмотря на то что в МАСе были выработаны определенные средства фиксации случаев этого рода, многие из них не нашли в нем своего отражения. Так, например, второе и третье значения слова бассейн не были снабжены пометами, указывающими на обязательное наличие у них определения или дополнения (первое значение может использоваться без них). В АТоСе этот недостаток в словарном описании был устранен:

БАССЕ́ЙН, -a, $\boldsymbol{M . ~ 1 . ~ О т к р ы т ы и ̆ ~ и л и ~ н а х о д я щ и и ̆ с я ~ в ~ з а к р ы т о м ~ п о м е щ е н и и ~ и с к у с - ~}$ ственный водоем, специально сооруженный для плавания, купания, проведения различных испытаний (например, судов) и др. целей. Плавательный бассейн. Городской бассейн. Бассейн фонтана. $\square$... Наверное, неплохо провести отпускнье дни, нежась в комфортабельном номере пятизвездной гостиницьи, купаясь в бассейне и изредка вылезая на свет Божий для похода по магазинам. И. Муравьева. Поспешай не торопясь. || Спортивно-оздоровительное учреждение с таким водоемом. Бассейн «Олимпийский». Купить абонемент в бассейн. Ходить в бассейн. Заниматься в бассейне.

2. чего или какой. Совокупность притоков реки, озера и т. п., а также площадь стока поверхностных и подземных вод в водоем (реку, озеро, море). Бассейн реки Волги. Страны Черноморского бассейна. ...

3. какой. Область залегания каких-л. определенных полезных ископаемых. Угольный бассейн. Железорудный бассейн. Нефтегазоносный бассейн. Соляной бассейн. ...

В предложениях Он выскочил на полчаса в магазин, Мне нужно выскочить за хлебом глагол выскочить характеризуется включенностью в предложно-падежные конструкции, не свойственные зафиксированным в МАСе другим значениям этого глагола, что послужило основанием для выделения в АТоСе у глагола выскочить смыслового оттенка 'ненадолго выйти, выбежать куда-л. с какой-л. целью; отлучиться', имеющего отчетливую разговорную окраску.

При обсуждении проблем словарного представления грамматики в АТоСе также достойна упоминания более тщательная фиксация фактов субстантивации, адъективации и адвербиализации (в некоторых случаях, как, скажем, в словах бывший и говорящий, эти процессы сопровождаются изменением лексической семантики слова), например:

БЫІ́ВШИЙ, -а я, -е е. 1. Прич. прош. от быть. 
2. ... || Ранее являвшийся кем-л., переставший занимать какую-л. должность, положение и т. п. Бывщий директор. Бывщий спортсмен. Бывщая жена. ... |в знач. сущ.. Разг. О прежнем муже, прежней жене: бы́вший, -е г о, м., одуш.; бы́вшая, -е й , ж., одуш. Восстановить отношения со своим бывшим. $\square$... У меня тоже ведь есть сын... Живет со своей матерью в Болшево. --- Хороший ребенок, но моя бывшая его перекармливает. Г. Щербакова. Lovecтория. Катя обернулась - там, на самом верху холма, стояли Зоя с бывиим. Т. Тронина. Никогда не говори «навсегда»;

ГОВОРЯ́ЩЩЙ, -ая, -ее. 1. Прич. наст. от говорить. ...

3. в знач. прил. Такой, который произносит слова, фразы подобно человеку. ... Из Москвы он привез детям подарки: крестнице своей Ляле он подарил говорящую куклу, Васе - пожарную каску. А. Пантелеев. Ленька Пантелеев. - Хотелось мне попугайчика говорящего купить, да все неподходящие, лопочут не по-русски. В. Шишков. Емельян Пугачев;

БЕЗНА́Л, -а , м. Разг. Безналичные деньги; безналичный расчет. ... | $в$ знач. нареч. по безна́лу, безна́лом. Заплатить безналом. $\square$ А весь наш многомиллионный бизнес строился только на живых деньгах - по безналу никто с кооперацией иметь дела не хотел. А. Тарасов. Миллионер.

Значительные усилия прилагаются для уточнения синтаксических характеристик слов и устойчивых сочетаний (особенностей управления, синтаксической функции и т.д.). Ср., например, использование грамматических помет в следующих словарных статьях:

БЁЛЫЙ ... $\diamond$ Белый и пушистый кто (неодобр., ирон.) - хороший и ни в чём не виноватый;

БОЛВӒНКА ... 2. чего, для чего и без доп. Проф. В различных ремеслах и производствах: кусок металла, дерева и т. п., представляющий собой заготовку для какого-л. изделия;

ГРОЗЙТЬ ... 1. (сов. пригрозить); кому чем, с неопр. или с придаточным изъяснительнылм. Предупреждать с угрозой о чём-л. тяжелом, страшном; угрожать.

Рассмотренные в докладе особенности подачи грамматической информации о слове в АТоСе не исчерпывают всей затронутой проблематики, но, как нам кажется, дают достаточно ясное представление о многообразии задач, стоящих перед лексикографами, и о необходимости усовершенствования традиционного грамматического описания лексики и фразеологии в ходе работы над новым толковым словарем русского языка.

\section{Литература}

$A T o C$ - Академический толковый словарь русского языка. Том 1: А - Вилять; Том 2: Вина - Гяур / Отв. ред. Л. П. Крысин. М., 2016.

$M A C$ - Словарь русского языка: В 4 т. / Под ред. А. П. Евгеньевой. 2-е изд., испр. и доп. М. : Русский язык, 1981-1984. 


\section{A. E. Tsumarev}

V.V. Vinogradov Russian Language Institute (Russian Academy of Sciences)

(Russia, Moscow)

zumarew@yandex.ru

\section{L.L.Shestakova}

V. V. Vinogradov Russian Language Institute (Russian Academy of Sciences)

(Russia, Moscow)

lara.shestakova@mail.ru

\section{PECULIARITIES OF THE PRESENTATION OF GRAMMATICAL INFORMATION ABOUT THE WORD IN THE NEW "ACADEMIC EXPLANATORY DICTIONARY OF THE RUSSIAN LANGUAGE”}

The article deals with some peculiarities of the presentation of grammatical information about the word in the new "Academic explanatory dictionary of the Russian language", which is one of the medium-sized explanatory dictionaries of Russian. The peculiarities under discussion distinguish the dictionary from previous four-volume "Dictionary of the Russian language" (so called "Small academic dictionary"), published by the Academy of Sciences in the early 1980s. Grammatical information about the word is contained in "Academic explanatory dictionary of the Russian language" in two parts of the dictionary entry - the zones of grammatical forms and grammatical characteristics. The dictionary provides more complete, obvious and consecutive information than the dictionary-predecessor. These qualities are achieved due to both systematic use of traditional lexicographic tools and the putting into operation of new tools and ways of description (for example the new label "oдyz.", i.e. "animate" is used). In particular, in the dictionary are consistently described: the presence of some grammatical word forms (for example short forms of adjectives), grammatical restrictions (in the case of some verbs - the lack of first and second person forms), peculiarities of syntactic government etc. The examples given in the article point out the need to improve the traditional grammatical description of vocabulary in development of the new explanatory dictionary of the Russian language.

Keywords: modern Russian standard language, grammar, grammatical norm, interaction of vocabulary and grammar, lexicography, explanatory dictionary, dictionary entry.

\section{References}

Akademicheskij tolkovyj slovar' russkogo jazyka [Academic explanatory dictionary of the Russian language]. Vol. 1: A - Vilyat'; Vol. 2: Vina - Gyaur / Ed. L. P. Krysin. Moscow, YaSK Publ., 2016 [AToS].

Slovar' russkogo yazyka $v 4 t$. [The dictionary of the Russian language in 4 vol.]. / Ed. A.P. Evgen'eva. $2^{\text {nd }}$ edition. Moscow : Russian language Publ., 1981-1984 [MAS]. 